\title{
Diseño curricular de un programa de Artes Visuales en modalidad virtual
}

\author{
Raúl Alejandro Martínez Espinosa \\ Sonia Alexandra Barbosa Ortiz ${ }^{2}$
}

\begin{abstract}
Resumen
El texto aborda nociones involucradas en los procesos de enseñanza - aprendizaje de las artes visuales a partir de una propuesta de diseño curricular en la modalidad virtual. Éste desarrolla aspectos de la relación entre los seres humanos y las artes visuales, para sustentar la necesidad de formar artistas que comprenden su entorno cultural y que provoquen transformaciones en él a partir de la creatividad y la expresión. A continuación se dedica al desarrollo del programa y las conexiones existentes entre el entorno, la técnica, la teoría, la creatividad, la sensibilidad y la obra, que contribuyen a la formación de artistas visuales autónomos comprometidos con su práctica y el entorno en el que viven.
\end{abstract}

Palabras clave: artes visuales, núcleo problémico, expresión digital, nuevos medios, virtualidad. 


\title{
Curricular program desing of Visual Arts in virtual mode
}

\begin{abstract}
The text incorporate notions involved in the teaching - learning of the visual arts, regarding a proposed of the curriculum design in virtual mode. It develops aspects of the relationship between the human and visual arts, to support the need to train artists who understand their cultural environment and causing changes in it, from the creativity and expression. The following text attempts to show the program's development and the connections between the environment, technology, theory, creativity, sensitivity and work, which contribute to the autonomous visual artists training, committed to their practice and the environment where they live.
\end{abstract}

Keywords: Visual arts, oriented problem, digital expression, new media, virtuality.

\section{Fundamentación teórica del programa}

Normalmente asumimos el término 'arte' como la actividad de manipulación de materiales y nociones artísticas (colores, líneas, sonidos, gestos, palabras, volúmenes, espacios) en búsqueda de expresión propia, que haga comunicable una interioridad subjetiva. Así mismo usamos el término 'estética' como el conjunto de facultades de conciencia subjetiva (la percepción, la sensibilidad, la imaginación y la creatividad). Lo estético, entonces, abarca un campo de actividad o pensamiento mucho más amplio que lo artístico. Siguiendo estas aclaraciones podemos decir que el arte es un espacio privilegiado de consolidación y experimentación de lo estético. Dado que en la creación artística se suspende el ejercicio cotidiano de la sensibilidad (estética) para dar paso al ejercicio especializado, las experiencias ordinarias que pasan al arte adquieren 
un carácter extraordinario. El arte puede servir para enseñarnos a valorar lo extraordinario, a saber que todo puede ser distinto, a respetar las diferencias, a convivir con el misterio y abrir la mirada a los mundos posibles.

En una época como la presente, poblada de conflictos de altos niveles de violencia y con medios de exterminio de alta eficiencia, se hace pertinente buscar toda posibilidad de cambiar las condiciones que suscitan la injusticia y la desigualdad; debemos construir en todos nosotros un carácter propicio para la solidaridad. El sentimiento de solidaridad se basa en la conciencia de la situación del otro (distinto a nosotros), cuya interioridad es tal vez el problema más complejo pero al tiempo el más natural e inherente al ser humano. Los "otros" no tienen que pensar como nosotros para ser considerados nuestros semejantes. Cuando ejercitamos la capacidad interior que nos permite sentir lo que sienten los otros, somos capaces de "ponernos en el lugar del otro", somos entonces una verdadera comunidad, una sociedad. Las artes visuales permiten desarrollar actitudes solidarias y cooperativas que posibiliten el respeto a las diferencias, la inclusión y en especial la capacidad y la voluntad de ponerse en el lugar del otro para aceptar, mejorar, modificar comportamientos con acciones en la vida propia, promover una mayor libertad y bienestar de la vida del otro.

Las artes visuales no sólo refinan la percepción y sensibilidad sino que también se han convertido en eje fundamental para el desarrollo del pensamiento crítico en la sociedad actual en la que cotidianamente se evalúan las interacciones, los espacios, la producción de imágenes manipuladoras que atacan perseverantemente la cotidianidad, formando sujetos deliberantes y propositivos que no solamente reciben información sino que están creando, haciendo hallazgos e intercambiando conocimiento con intenciones de cambios positivos en la sociedad.

Por otro lado, el artista visual dispone de diferentes medios para potenciar la expresión y la sensación en relación con el proceso que involucra a su obra. El contexto dentro del que se desenvuelve su quehacer responde a unas condiciones sociales, políticas y económicas que están signadas por lo que el filósofo francés J. F. Lyotard llamó posmodernidad. En la actualidad, los intereses de la producción artística están atravesados por este contexto dentro del cual se desarrollan las obras, es decir un ámbito político, social, económico y cultural en donde prima la globalización y la conectividad. Un momento histórico llamado posmodernidad, esto para designar fenómenos que no responden al contexto de la era industrial y los mass media, los signos de la modernidad, la época de los grandes sistemas políticos e ideologías. Actualmente se vive un momento de crisis de los sistemas y reconfiguración del orden mundial. En las artes visuales convergen por lo tanto algunas características comunes a las prácticas artísticas y el contexto sociopolítico y cultural, a saber: experimentación, intervención de los espacios, eclecticismo, las redes y los colectivos, los espacios expositivos y la globalización entre otros. Algunos colectivos de artistas y foros de discusión como el decolonialismo presentan resistencia ante el lado homogenizador de la cultura global rescatando los valores locales. 


\section{Diseño curricular del programa de Artes Visuales en modalidad virtual}

De acuerdo con el Modelo Pedagógico Unadista, las características del currículo en la UNAD constituyen una posibilidad de interacción en diversos ambientes de aprendizaje entre estudiantes, saberes, profesores y contextos para la construcción de conocimiento y la formación integral, lo cual permite la reflexión, la comprensión y la transformación de realidades (PAPS, 2011).

El plan de estudios para el programa de Artes se estructura a partir de la identificación de núcleos problémicos (NP) es decir, ejes conductores que organizan la información de manera coherente y lógica como una forma de abordar los problemas, requerimientos, necesidades contextuales locales, regionales y globales cuyas respuestas dadas desde las artes tengan repercusión en el ámbito cultural y social por medio de la reflexión, el análisis y la actitud crítica, creativa y propositiva.

Para la identificación de los núcleos problémicos (NP) se realizó la siguiente ruta metodológica, Figura 1, que comenzó con diversas estrategias metodológicas tales como entrevistas a artistas visuales y teóricos del arte; revisión bibliográfica y dialogo de expertos. A partir de la información obtenida se propusieron una serie de preguntas generadoras alrededor de los problemas de la disciplina en la actualidad. Una vez formuladas las preguntas se nominaron los núcleos y posteriormente se procedió a definir su manifestación en articulación con las competencias y perfiles de formación del programa. Después de contar con cuatro NP se trabajó en la definición de un núcleo integrador de problemas (NIP), entendido como la convergencia de las problemáticas abordadas por el programa y en última instancia constituye su máxima aspiración formativa.

Figura 1. Ruta metodológica para la construcción de NP y NIP.

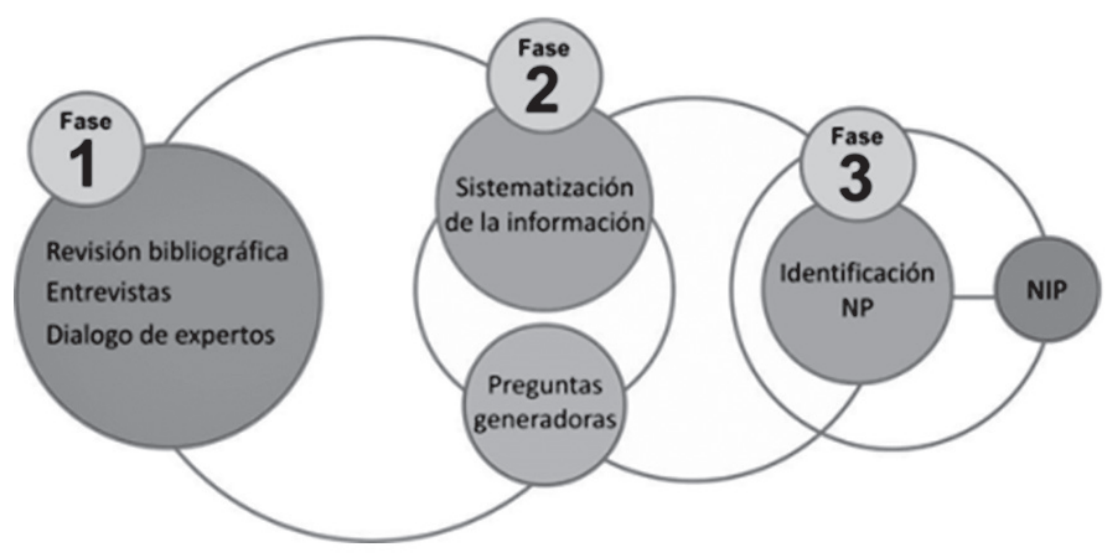




\section{NP1. Pensamiento artístico y transformación de la expresión visual}

Pregunta generadora: ¿Cómo el contexto histórico y social permite expresar las características propias de los constructos sociales y comunitarios, mediante el aporte de la reflexión sobre la producción de las manifestaciones artísticas y culturales?

Aunque en arte no se deben interpretar sin más, políticamente las características formales, también es verdad que no existe en él nada formal que no tenga sus implicaciones de contenido y éste penetra en el terreno político. En la liberación de la forma, tal como la desea todo el arte nuevo que sea genuino, se esconde cifrada la liberación de la sociedad, pues la forma, contexto estético de los elementos singulares, representa en la obra de arte la relación social. Por eso una forma liberada choca contra el status quo (Adorno, 1983, págs. 332-333).

Los constructos comunitarios generan cultura. Este fenómeno está signado por la dinámica, la interactividad y el intercambio acerca de las diferentes miradas sobre el mundo; así como la construcción de identidades compartidas y lazos de convivencia. Vínculos que surgen desde el individuo inserto en un contexto determinado y que se proyectan hacia el grupo identitario, lo cual permite su reafirmación como sujeto comunitario. Parafraseando a Carlos Vasco en su libro Algunas reflexiones sobre la pedagogía, es importante tener en cuenta el contexto en que se desarrolla el ser humano, es decir, no es un asunto de escuela sino de sus macro entornos y micro entornos los que intervienen en la educación.

Cada período histórico posee rasgos propios que constituyen el universo simbólico que permite construir cultura y por ende, sociedad. Cada campo de saber debe acceder al origen de su conocimiento. Por tal razón y siendo éste, objeto de indagación, debe construir un conjunto articulado e integral. Lo anterior con el objeto de soportar y producir un nuevo conocimiento que propenda el fortalecimiento de los constructos comunitarios y de la producción artística en los mismos.

El arte, en tanto generador de cultura, se vale de los diferentes saberes nacidos en el seno de la actividad creativa y la tradición (en algunas ocasiones para generar rupturas con la misma). El resultado de lo anterior permite la conformación de un corpus teórico-conceptual, generador de pensamiento artístico, por cuanto recoge las experiencias locales, regionales, nacionales y globales para la producción del mismo, en un proceso que sistematiza experiencias sociales manifiestas en el período de creación, inserto en la reflexividad sobre los procesos creativos y su influencia desde una perspectiva crítica de los mismos.

\section{NP2. La expresión artística y los medios en la era digital}

Pregunta generadora: ¿Cuál es la injerencia de los nuevos medios y las TIC en los procesos artísticos y la construcción de cultura en la sociedad contemporánea? 
La sociedad contemporánea está conformada por el concierto de diversas voces y matices surgidos en el seno de las diferentes comunidades que la cimientan. En esta diversidad se desarrollan múltiples saberes nutridos desde el ámbito local y el ejercicio cotidiano. Dichos ámbitos tienen una extensión e interacción global gracias a las tecnologías de la comunicación y las comunicaciones. Los medios para la producción e intercambio de información se valen de las TIC y las redes sociales para la construcción de conocimiento y saberes.

Por primera vez, la historia va a desarrollarse dentro de un sistema de tiempo único: el tiempo global. Hasta ahora la historia transcurría dentro de tiempos locales, estructuras locales, regiones y naciones. Pero ahora, en cierto modo, la globalización y la virtualización están inaugurando un tiempo universal que prefigura una nueva forma de tiranía. Si la historia es tan rica, es debido a que era local, esto es, gracias a la existencia de tiempos limitados espacialmente que no hicieron caso a algo que hasta ahora sólo ha ocurrido en la astronomía: el tiempo universal. Pero en un futuro muy cercano, nuestra historia sucederá únicamente en tiempo universal, que es el resultado de la instantaneidad (Virilio, 1995).

La interconectividad suscita en la actualidad nuevas formas de comunicación que modifican todas las dimensiones del individuo y constituyen un rasgo propio de la era de la información y la cultura digital. El desarrollo y refinamiento de los medios de comunicación e información en los que el sujeto desempaña cada vez un papel más activo en la producción de contenidos, están configurando nuevas comprensiones acerca de la interrelación del individuo con su entorno sociocultural y la naturaleza, debilitando las fronteras que tradicionalmente han dividido sujetos de enunciación y objetos de estudio en las relaciones interculturales. La era de la información que acontece en la actualidad suscita y afecta profundas transformaciones sociales y la producción de cultura.

La producción de imágenes en la actualidad vive el predominio de las tecnologías digitales en remplazo de las análogas. El fenómeno anterior ha hecho posible que el acceso a dispositivos tecnológicos sea más asequible y ha acelerado los procesos que involucran la producción, manipulación y difusión de imágenes visuales y diversos contenidos. Los procesos de creación artística se acompañan de cambios e innovaciones tecnológicas que modifican los usos y costumbres relacionados con éstos.

Cada época o período histórico se caracteriza por el aporte de nuevas "formas técnicas" que hacen posible la sensibilidad expresiva y que paulatinamente se convierten más que en un medio para la creación, en los escenarios donde se produce el arte. De igual forma, las TIC permiten el surgimiento de formas de democratización del conocimiento e inclusión de diversos saberes (wikis, blogs, entre otros), en tanto se emplean medios de amplia difusión y alcance. 
El artista no puede escapar a la dinámica de los avances tecnológicos que han cambiado nuestro modo de vida de una manera fundamental y ser ajeno a la influencia de todos los procesos de transformación que pueden incidir en la actualidad, de una manera directa o no, en su forma de expresión (Díaz M, 2007, pág. 49).

Tecnologías como la escritura, la representación visual, la producción objetual y el archivo y producción de información mediada tecnológicamente potenciaron las necesidades creativas y expresivas del ser humano; en el ámbito actual dichas tecnologías están mediadas por la tecnología digital. La producción artística en el ámbito de las artes digitales alcanza posibilidades de expresión y factura que se reflejan en una mayor velocidad y que por lo tanto requiere unas competencias técnicas nuevas que potencien la sensibilidad creativa del artista. Los nuevos medios y las tecnologías de la información y la comunicación han modificado la relación obra-museo-espectador, debido a que los en los nuevos medios de difusión predominan las redes cómo internet y el impacto de la producción artística se direcciona desde una identidad local a unas redes globales.

\section{NP3. La creación, promoción e investigación artística como alternativa de conocimiento}

Pregunta generadora: ¿Cómo influye el conocimiento de las prácticas artísticas $y$ comunitarias en la concepción y desarrollo de procesos alternativos de investigación?

La expresión artística en este medio se puede llegar a niveles vivenciales y altamente participativos de interacción con el espectador. Con los multimedia se inicia un nuevo tipo de escritura interactiva, que al romper con la linealidad, plantea el desafío de pensar, y programar, múltiples opciones de creación por los artistas contemporáneos (Díaz M, 2007, pág. 47).

La comunidad es fuente de conocimiento, por cuanto permite el intercambio significativo de saberes gestado en la experiencia y ejercicio cotidiano de interacción con el medio y las personas. En consecuencia, la experiencia comunitaria deviene única en lo que a sus características se refiere y también el conocimiento gestado en ella. Cada ámbito de saber debe ser abordado según sus particularidades, razón por la cual es procedente buscar y acceder a fuentes y procesos de investigación que construyan el cuerpo teórico que le es propio.

El arte requiere métodos y procedimientos singulares para adelantar procesos de investigación. En artes se puede mencionar dos vertientes de investigación: La primera corresponde a la práctica artística en si (investigación-creación) y la segunda a la investigación acerca del arte, los artistas y los periodos del arte, cuya denominación se ha convenido en llamar "Teoría del arte". La planeación, 
desarrollo y exposición de una obra de arte, en sí misma, constituye un proceso investigativo. En este proceso se potencia el taller experimental como medio individual y colectivo para la exploración, análisis y producción de la obra de arte tanto del artista como intérprete del momento histórico, cultural y social del cual emerge y su consecuente proceso de presentación, recreación y transformación. Esto permite fortalecer el diálogo de expresiones sensibles y experiencias creativas, que surgen desde sus experiencias comunitarias.

En lo concerniente a la vertiente de investigación acerca del arte y los artistas se debe anotar que requiere de unos métodos y metodologías en las que se busca aportar a la reflexión y producción académica tanto de diversas manifestaciones culturales como a la gestación y transformación de diversas identidades culturales, que se generan dentro de las comunidades y tienen marcadas influencias de la tradición, las manifestaciones contemporáneas y el intercambio cultural en un mundo globalizado.

Así mismo, tanto la investigación-creación (taller) como en la investigación acerca del arte permiten procesos de indagación sobre las transformaciones intra e intersubjetivas surgidas durante los momentos creativos, convirtiéndose en promotores y dinamizadores de la construcción de conocimiento. Lo anterior a su vez genera intercambio de saberes académicos, culturales y artísticos significativos. De igual manera, propone una mayor complejidad del universo simbólico generador de cultura y sociedad.

Ahora bien, tanto en el proceso creativo como en la indagación del mismo intervienen dinámicas cognitivas que producen una forma diferente de conocimiento, el cual permite explorar las posibilidades de búsqueda, imaginación e invención del artista, que no implica solamente el pensamiento lineal, predictivo, lógico y racional manifiesto en el lenguaje discursivo formal, sino otras funciones cognoscitivas tales como las pulsionales y las afectivas (instinto, sentimiento y la emoción) siendo componentes en la promoción del pensamiento complejo. Las que, junto con la función racional, recrea al ser humano por cuanto potencia y renueva su cualidad sensible, cimiento de su identidad y por tanto de la cultura. En consecuencia, se puede decir que el arte genera nuevas formas de conocimiento que implica una re-evaluación de la comprensión y sistematización del mismo.

\section{NP4. Arte, identidad y transformación cultural}

Pregunta generadora: ¿Cuál es el impacto de la producción artística en la construcción de identidad desde el ámbito local, regional, nacional y global en la sociedad actual?

...en la era digital, así como en otras épocas los artistas se anticipan a su tiempo. Cuando aparecen nuevos soportes y recursos técnicos ellos son 
quienes siempre toman la delantera en la exploración de las posibilidades que se abren para la creación. Allanan esos territorios considerando la regeneración de la sensibilidad humana para que nuestros sentidos y nuestra inteligencia habiten y transiten en nuevos ambientes que, lejos de ser simplemente técnicos, son también vitales. Son los artistas quienes señalan las rutas hacia la adaptación humana a nuevos pasajes que serán poblados por la sensibilidad (Santaella, 2007).

La sociedad contemporánea se caracteriza por grandes y aceleradas transformaciones económicas, culturales y tecnológicas. Dicha celeridad ha producido un debate significativo en la sociedad fluctuante entre la constitución de diversas realidades y la homogenización. La diversidad se construye desde la cotidianidad y constantemente recrea, desde lo local, la cultura global. En este sentido, surgen posibilidades desde lo local como escenario donde es viable contrarrestar los efectos de la creciente uniformidad de la sociedad contemporánea. La homogenización. El fortalecimiento de la identidad surgida desde el ámbito local permite "regionalizar" las experiencias surgidas en la comunidad, esto, con el propósito de reivindicar el cuerpo cultural diferenciador que da presencia a narrativas que promueven la diversidad, la diferencia y el acercamiento a otras realidades personales y sociales. El fortalecimiento de la identidad comunitaria opera como resistencia a la pérdida paulatina de los límites culturales que trae la globalización; en este sentido, la interconectividad e intercambio de sensibilidades se da desde una perspectiva más igualitaria en la medida en que el flujo es bidireccional, el sujeto recibe información y también pone información.

La interactividad provocaría un cambio profundo e inesperado en las relaciones con el computador, no solamente del artista sino del espectador, pues se tenía la posibilidad de introducir en el computador una serie de informaciones no previstas dentro de los programas y provocar así una modificación casi inmediata (en tiempo real) de los resultados (Couchot, 2005, pág. 42) [...] la obra [de arte interactiva] no tiene existencia, a no ser que el espectador la intervenga. El espectador es convocado a "hacer la obra", a su manera - con mayor o menor invención, curiosidad, complicidad, inteligencia o astucia (pues muy rápidamente éste ensaya a engañar al programa o a probar sus límites)- pero esto siempre sobre la iniciativa del autor del dispositivo. El espectador actualiza los posibles de la obra (Couchot, 2005, pág. 43).

El arte es generador de cultura y, por ende, de identidad y sociedad, por cuanto, a partir de la renovación del individuo y la construcción del sujeto social y comunitario potencia, en primera instancia, el perfeccionamiento de las dimensiones intra-personales relacionadas con el auto- conocimiento del ser humano en relación con sus emociones, sentimientos, percepciones y su dimensión intelectual, en tanto facilita el desarrollo de su capacidad de 
representación simbólica y la optimización de ésta por medio del uso de la tecnología, en aras de mejorar sus condiciones expresivas. En segunda instancia, posibilita el desarrollo de su dimensión social, que permite entablar relaciones de diálogo y convivencia por medio de la práctica de la cooperación, la valoración de las actuaciones ajenas y el desarrollo de la solidaridad. De esta forma, potencia la recreación y transformación del entorno social, cultural y la cimentación del ejercicio político, en cuanto modifica por medio de una acción vital creadora, abierta a otros ámbitos de actividad y convoca al desarrollo de un artista integral con capacidad de abordar el conocimiento desde diversas miradas, contrarrestando el efecto devastador de una educación tecnicista e hiperespecializada tendiente a perpetrar modelos económico-políticos excluyentes y poco participativos, reivindicando, tal como lo expone Estanislao Zuleta "la potencia educadora del arte como fenómeno político” (Zuleta, 2004, pág. 133).

Por su parte, las imágenes, acontecimientos, investigaciones, etc. devienen en producto cultural que refleja la concepción tanto subjetiva como objetiva de una idea, concepto o símbolo, de acuerdo con un contexto histórico y social específicos y en cuya creación intervienen medios, hijos de modelo o novedad tecnológica propia de una época que aporta nuevas formas y técnicas que posibilitan el desarrollo de la expresión y creatividad y que paulatinamente se convierten en el ámbito donde se genera el arte, más que en un medio de expresión. Así, las artes visuales, por medio de la producción creativa de imágenes, experiencias, conocimientos y la utilización de diversos medios tanto en su realización como su difusión, se erigen como manifestación y generación de identidades surgidas en el seno de las comunidades que trascienden lo regional y nacional, para insertarse en la globalidad como una oportunidad de presencia y posicionamiento de las diversas miradas sobre el mundo, la cultura y la sociedad.

Una vez formulados los núcleos problémicos se destacan ideas generales que abarcan las problemáticas centrales de los mismos en manifestaciones, las cuales constituyen las ideas fuerza del núcleo problémico y estructuran el eje transversal de los contenidos de las redes académicas.

\section{Principios de formación, competencias y perfiles definidos para el desarrollo del programa}

\section{Propósitos de formación}

Desde el programa de Artes Visuales en la UNAD se propone la formación permanente de un artista visual autónomo, con espíritu crítico y creativo frente a su quehacer en el campo de las artes digitales y los nuevos medios. Un artista capaz de contribuir a la comprensión y trasformación del entorno cultural, por medio de la articulación de su universo experiencial personal, social y 
profesional, con los conocimientos de orden disciplinar de los nuevos códigos que inciden y potencian la creación artística.

El programa también tiene el propósito formativo de favorecer el intercambio disciplinario de saberes, experiencias y técnicas, toda vez que expresan diversas realidades, sujetas de expresión sensible por medio del lenguaje artístico, partiendo de la concepción de que la educación en artes visuales es de vital importancia para la formación integral del ser humano, puesto que promueve el desarrollo de las dimensiones humanas fundamentales en tanto potencia las posibilidades expresivas, emocionales y creativas. Así mismo, desde el programa de artes visuales se impulsa la consolidación de la identidad tanto personal como social, por medio del incremento de valores dentro de las diversas culturas tales como la tolerancia, la solidaridad, el respeto a la diferencia, el rechazo a la violencia, ya que las manifestaciones artísticas procuran el desarrollo humano y social, además de promover una mirada reflexiva y el refinamiento de la sensibilidad que incentiva la formación del sujeto político y crítico de la realidad.

El programa de Artes Visuales se enmarca dentro de unos propósitos institucionales que son transversales a las diferentes Escuelas. De esta manera, la UNAD suscita el aprendizaje autónomo que comprende el desarrollo de procesos de autorregulación, de trabajo independiente, de desarrollo de actividades académicas y sociales que implique la autodisciplina (PAP Solidario, pag.12), con miras a promover la apropiación crítica del entorno social, cultural, personal por medio de la construcción de conocimiento y la autorreflexión, base para el ejercicio vital, en cada una de sus dimensiones: privada, social, académica, profesional, consciente y contextualizado, que en el ámbito de las artes visuales se evidencie en una formación autogestionada y permanente en los aspectos técnicos, teóricos y prácticos durante tres momentos, a saber:

1. La apropiación crítica de la realidad y del conocimiento existente, como reconocimiento de las características del entorno y del potencial propio del protagonista del proceso formativo.

2. La construcción creativa del conocimiento, mediante el desarrollo y consolidación de estructuras mentales que se conviertan en vehículos que afiancen procesos de descubrimiento, análisis y aplicación teórica y conceptual del conocimiento.

3. La aplicación práctica del conocimiento, como evidencia de la aprehensión del mismo, por medio de su aplicación en diversos contextos, lo cual permite la conformación continua de identidad cultural en un mundo global.

\section{Perfiles de formación}

El maestro en Artes Visuales de la UNAD orienta su práctica artística en el ámbito de las artes digitales y los nuevos medios con una actitud crítica, 
creativa y reflexiva. Tiene además la capacidad de crear, dirigir, planear, liderar y desarrollar procesos relacionados con la imagen (video, cine, televisión, procesos multimediales y editoriales) de carácter artístico, investigación en artes y gestión cultural.

\section{Perfil del egresado}

- Un profesional capacitado en su campo profesional, cuya producción artística se fundamente en la reflexión, la crítica, la investigación y en el conocimiento y manejo de los diversos medios y técnicas en la era digital.

- Un artista creativo, con aguda sensibilidad, con una sólida formación tanto teórica como práctica, tanto para la para la creación artística en el campo de las artes digitales, como para la crítica de dicha producción y revisión de los objetos y medios de creación artística.

- Un agente social transformador y comprometido con la dinámica del país en la construcción de nación y ciudadanía, capaz de desempeñarse en diversos escenarios de la vida productiva tanto en el ámbito creativo, como en la producción de diversos proyectos visuales y culturales en los que la aplicación de la tecnología digital tenga un carácter medial y crítico en cuanto a sus aplicaciones y posibilidades creativas.

\section{Perfil ocupacional}

- Orienta su práctica artística en el ámbito de las artes digitales, los nuevos medios y las nuevas tecnologías con una actitud crítica, creativa y reflexiva.

- Cuenta con la capacidad de crear, dirigir, planear, liderar y desarrollar procesos de carácter artístico y gestión cultural.

- Actitud investigativa para la producción teórica de conocimientos en prácticas y procesos artísticos y de artistas.

- Puede desempeñarse en la dirección de proyectos relacionados con la imagen en el campo del video, el cine, la televisión, procesos multimediales y editoriales. - Lidera proyectos comunitarios en artes tanto en el ámbito local cómo regional.

- Tiene la capacidad de ejercer prácticas curatoriales e impulsar procesos artísticos de carácter regional con un impacto nacional.

\section{Competencias}

El programa de artes visuales formula cuatro competencias generales, las cuales constituyen la impronta de formación del egresado, estas son:

1. Significa contenidos de carácter teórico que el artista requiere en aras de adquirir una formación universal que fundamente su práctica y suscite una reflexión permanente alrededor de su quehacer como artista y el contexto en el que se desarrolla su obra desde una perspectiva histórica. 
2. Crea y produce imágenes visuales a partir de temáticas y problemáticas del propio entorno y contexto, con un dominio y manipulación efectiva del material, la técnica y los medios.

3. Construye el sentido de la investigación propia de las artes en las que analiza, interpreta, gestiona y participa activa y permanentemente en procesos tanto investigativos como de formación que potencian la creatividad y la autogestión de conocimiento.

4. Dimensiona y aplica un sentido crítico sobre los aspectos relevantes del entorno social y profesional donde se desempeña para fomentar aspectos solidarios y comunitarios que generen impacto del arte en la sociedad.

\section{Competencias del estudiante de artes visuales}

Las Competencias del estudiante se definen a partir de la tipología propuesta en el Proyecto Académico Pedagógico Solidario (PAPS) como apuestas de la formación en la UNAD. "expresa una dimensión de futuro e implica un proceso permanente de reflexión, investigación y construcción colectiva de diferentes alternativas y posibilidades pedagógicas, para la apropiación crítica y creación constructiva del conocimiento” (PAPS, Versión 3.0, pág. 95).

\section{Competencias Comunicativas}

- Expresa el sentido y significado de su práctica artística haciendo uso de la teoría y la historia del arte.

- Apropia e interpreta contenidos de carácter teórico que el artista requiere en aras de adquirir una formación universal que fundamente su práctica.

- Desarrolla sensibilidades creativas mediante la producción artística.

\section{Competencias Transversales}

- Utiliza herramientas digitales para la creación de obra.

- Participa permanentemente en procesos formativos que potencien la creatividad y la autogestión de conocimiento.

- Desarrolla sentido crítico sobre los aspectos relevantes del entorno social y profesional donde se desempeña.

- Reconstruye la realidad social desde la dimensión artística

\section{Competencias Profesionales}

- Crea imágenes visuales a partir de temáticas y problemáticas del propio contexto, espacio y tiempos específicos.

- Produce formas diversas de pensamiento visual y percepciones particulares acerca de los diferentes contextos, por medio de la expresión visual y digital.

- Argumenta y potencia la sensibilidad ante los medios en los que desarrolla su producción artística. 
- Articula contextos, materiales y lenguajes visuales en la producción artística. - Desarrolla la capacidad para auto gestionar proyectos artísticos propios y colectivos.

\section{Competencias Específicas}

- Conoce y aplica las técnicas de análisis crítico de las imágenes visuales como parte fundamental del proceso creativo.

- Maneja, manipula y domina los materiales y los medios para la creación artística.

- Resuelve problemas temporales y espaciales inherentes a la producción artística tales como el emplazamiento o la exposición.

\section{Plan General de Estudios del Programa}

El programa se enmarca en los lineamientos curriculares de la universidad para el diseño de programas. En este ámbito se definen los niveles de construcción curricular para los programas de la UNAD, donde se especifican el Macrocurrículo, que expresa las directrices institucionales en torno al concepto de ser humano y tipo de sociedad que la UNAD aspira a construir, garantizando la pertinencia y globalidad de la formación. El Mesocurrículo representado en la construcción de mapas curriculares que evidencian la interacción entre los campos de formación y los propósitos formativos de un programa académico; y el Microcurrículo entendido como la interacción de las dimensiones del modelo pedagógico que materializa el enfoque didáctico de la UNAD, orientado a la consolidación de procesos de aprendizaje significativo, colaborativo y autónomo. A partir de estos lineamientos se estructura por campos de formación articulados en torno a problemas y por competencias, organizado desde el sistema de créditos académicos.

El programa cuenta con un NIP (núcleo integrador de problema) y NP (núcleos problémicos) con sus respectivas redes académicas que a su vez están conformadas por cursos académicos de diversos tipos y campos de formación. El estudiante inicia con una serie de cursos que corresponden al campo de la fundamentación (cursos básicos de carácter teórico y práctico relacionados con historia y teoría del arte, así como diseño básico, dibujo y video entre otros) posteriormente se avanza a la profundización en donde el estudiante opta por un área específica para el desarrollo de su práctica con tres áreas disciplinares previas a los talleres integrales, a saber: Expresión digital, Gráfica y pintura, y, Espacialidad. Cada una de estas áreas ofrece cursos académicos que el estudiante puede tomar como electivos previamente a los talleres de creación. 


\section{Revista de}

investigaciones UNAD

Volumen 14. Número 1. Junio 2015

Figura 2. Estructura Curricular del programa de artes visuales.

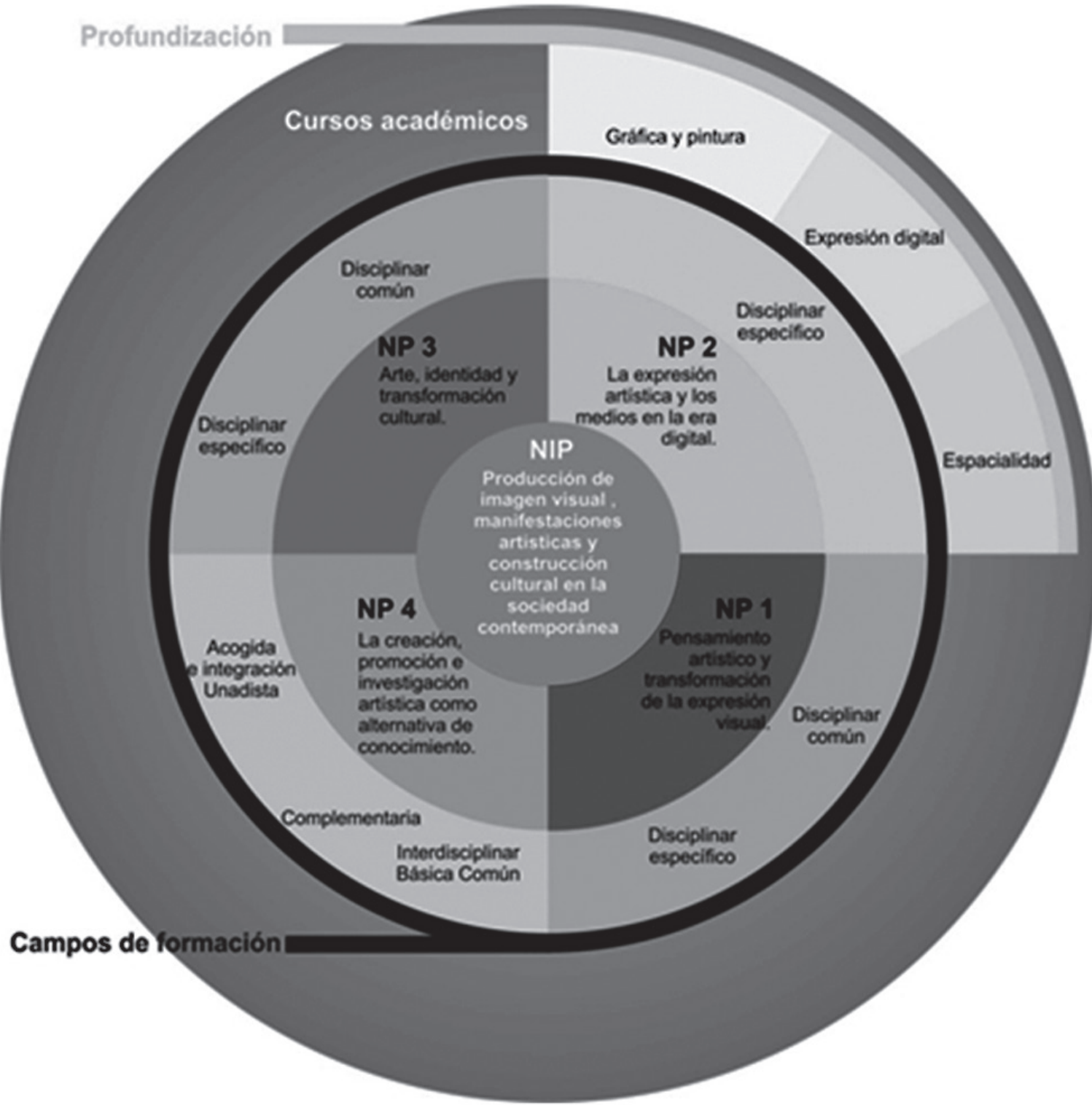

*El estudiante requiere de 150 aprobados para optar al título de maestro en artes visuales. 
El mapa curricular establece diversas rutas académicas para transitar el programa de formación; así mismo define las orientaciones para el proceso formativo del estudiante. En cada periodo académico el estudiante puede cursar un máximo de 18 créditos académicos y durante el intersemestral el estudiante podrá cursar un máximo de 8 créditos académicos. Es importante mencionar que existen tres grupos de cursos (fundamentación, profundización y creación) dentro de los cuales los estudiantes pueden asumir la ruta académica que consideren pertinentes con sus requerimientos. En el periodo de profundización el estudiante puede optar por tres redes de cursos de profundización.

\section{Contenido general de las actividades académicas}

La UNAD cuenta con una amplia trayectoria en el diseño de enfoques, métodos, técnicas y herramientas que le permiten a sus programas promover, de una manera efectiva, el aprendizaje autónomo. El programa de artes visuales asume la orientación de las actividades académicas en el marco de la formación e-learning en ambientes virtuales de aprendizaje (AVA) y se organiza a partir de los siguientes elementos:

\section{Redes de cursos}

En el programa de artes visuales existen dos tipos de redes: La red de cursos, están conformadas por el director de curso y los tutores; y las redes académicas que dinamizan la gestión curricular del programa. Estas las redes se organizan de acuerdo con las etapas de formación del proceso artístico, es decir, fundamentación, profundización y creación. Durante la fundamentación y profundización las redes se organizan básicamente por cursos de teoría e historia del arte, práctica artística y formación interdisciplinar. En la profundización se enfatiza en las redes de cursos metodológicos (espacialidad, expresión digital y gráfica y pintura) y se mantienen las de fundamentación. Finalmente se enfatiza en la red de creación, es decir el proceso del taller.

\section{El curso académico}

El curso académico se constituye en la unidad estructural de la formación. Además del sistema de créditos académicos, áreas o campos de formación, los cursos académicos hacen parte esencial de la estructuración curricular y se constituyen en la unidad pedagógica y didáctica que articula el aprendizaje y la formación.

Referido al orden de lo teórico o de los fundamentos, el curso académico tiene que ver con la identificación y reconocimiento de las problemáticas, perspectivas teóricas, tendencias, enfoques, conceptos, categorías, métodos y técnicas, indispensables para la sedimentación del suelo que configura la disciplina, interdisciplinar o transdisciplinar relacionada con el curso y los aspectos 
específicos que, en un momento determinado, integran el respectivo campo disciplinario. El programa de artes visuales emplea tres tipos de cursos: cursos teóricos, metodológicos y prácticos.

En términos pedagógicos, el curso de carácter teórico enfatiza de manera más evidente en el desarrollo de operaciones metacognitivas y en las actualizaciones cognitivas. Con respecto al orden de lo metodológico, el curso académico está constituido por un conjunto de procedimientos, estrategias, técnicas $\mathrm{y}$ herramientas identificables y sistematizables que posibilitan tanto el reconocimiento del ordenamiento que hace posible el desempeño y el ejercicio de determinadas prácticas profesionales, oficios u ocupaciones, como las problemáticas que emergen a partir de las modificaciones de los contextos, escenarios y ambientes en los que se realizan las actuaciones y se ejercen las competencias laborales u ocupacionales, al igual que la identificación de las nuevas exigencias y requerimientos formativos.

En el programa de artes visuales, el curso práctico refiere al taller integral como el espacio inherente y necesario para la creación de la obra de los estudiantes. Esta tipología de cursos aborda problemáticas que atraviesan y configuran lo actual, lo contemporáneo, lo emergente, los flujos que suceden en el orden de los acontecimientos, la eventualidad y el momento presente abordados por el artista en su proceso de creación artístico. En este orden de ideas se vincula el presente con la tradición, sus diferentes problemáticas y prospectivas. El taller integral, como estrategia metodológica, promueve la producción de obra de una manera dinámica en donde el tutor acompaña de manera efectiva el proceso de creación con el objetivo de exponer los resultados y difundir la obra en los espacios que para tal fin dispondrá la universidad.

\section{Enfoque didáctico}

La estrategia didáctica y pedagógica del taller, donde el estudiante desarrolla la habilidad para resolver los problemas inherentes a la práctica artística, requiere la aplicación de conocimientos y habilidades de orden teórico y práctico. Para llegar a los cursos prácticos es importante haber cursado cursos teóricos y metodológicos. Durante el proceso de creación el estudiante requiere un acompañamiento permanente por parte del tutor sobre los avances y progresos en la creación de la obra. A través de la experimentación y consolidación de los avances en la configuración de la obra, el estudiante puede registrar, contrastar y desarrollar estrategias que le permitan presentar el proyecto de creación para ser evaluado mediante la estrategia de tutorías colegiadas y una vez solventado este requerimiento circular la obra en los circuitos globales que hace posible la red a través del Museo Virtual Unadista. 
Figura 3. Estructura del taller como eje de producción artística.

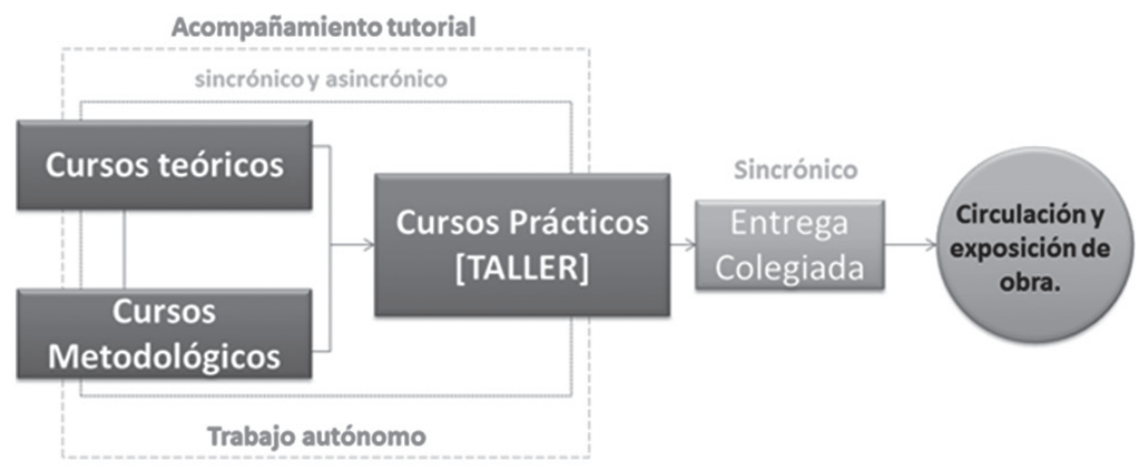

\section{El material didáctico}

Su propósito básico es apoyar el trabajo académico del estudiante mediante la planificación de los procesos de aprendizaje, acorde con las competencias y finalidades formativas formuladas en los diferentes cursos académicos que integran los diversos campos de formación de sus programas.

Los principios que guían la construcción de materiales didácticos son los siguientes:

- La didáctica como herramienta para el aprendizaje autónomo, significativo y colaborativo.

- La didáctica como enlace entre las lógicas disciplinarias y las lógicas pedagógicas orientadas a la formación integral y el desarrollo de las competencias.

- El material didáctico como eje dialogante y tránsito entre lo local y lo global.

- El material didáctico de los cursos académicos como unidad fundamental de la formación.

- Condiciones específicas para la elaboración de materiales didácticos de cursos académicos: estandarización e indicadores.

- El material didáctico de los cursos académicos como generador de competencias generales, específicas y transversales para el desempeño.

- El material didáctico como dispositivo para la creación de las redes académicas entre docentes de carrera y ocasionales (tutores y consejeros) y estudiantes.

La producción del material didáctico exige tener en cuenta los componentes estructurantes y los elementos estructurales que lo constituyen; estos últimos 
determinan los pilares de la estructura arquitectónica del material didáctico, y tienen que ver con la pedagogía, la didáctica, la temática, las interactividades, la metodología, la evaluación, la tecnología y lo documental.

\section{Conclusiones}

Los procesos de enseñanza y aprendizaje en las artes visuales son posibles en la modalidad virtual gracias a la implementación de nuevas tecnologías de información, comunicación e informática. La formación de artistas a través de dicha modalidad, trasciende la territorialidad urbana y permite la inclusión de regiones con las particularidades propias para la creación y producción de obras con referentes propios del entorno cultural y social del artista.

Mucho está ocurriendo actualmente en la educación artística, ya que es permanentemente posibilitadora de espacios de reflexión que confrontan al ser humano, y por lo tanto produce cambios en las comunidades y su entorno, esto es lo que la hace necesaria en la formación de seres humanos íntegros.

El uso creativo de los nuevos medios a fomentado la interactividad entre los seres humanos, éste intercambio de información y de saberes contribuye enormemente a la expansión de sus fronteras y por lo tanto a la ampliación del conocimiento.

Tanto los investigadores teóricos del arte, como los que están investigando a través de la práctica, buscan constantemente metodologías que proporcionen una visión de saberes colectivos e individuales que mantengan la capacidad de reflexión de manera crítica y ética. Las producciones artísticas se construyen desde la cotidianidad y esto se traduce en la relación que existe entre las intenciones de las creaciones que son circunstancias que aportan el sentido desde el cual el artista concibe su trabajo, y las posibilidades técnicas que son el vehículo de interacción entre el espectador y el público. Inevitablemente estas producciones se insertan en el mundo dando a conocer una cultura, un contexto (condiciones sociales, creencias religiosas, delimitaciones espaciales, entre otros), que producen nuevas preguntas y por lo tanto nuevos conocimientos y transformaciones en el tejido social. 


\section{Referencias bibliográficas}

Adorno, T. 1983. Teoría Estética. Barcelona: Orbis.

Couchot, E. 2005. El arte interactivo: de la combinatoria a la autonomía. En I. Hernández García , Estética, ciencia y tecnología (págs. 40-46). Bogotá: Editorial Pontificia Universidad Javeriana.

Díaz M, M. L. 2007. Arte y diseño multimedia el cruce entre dos maneras de entender el mundo. En J. La Ferla, El medio es el diseño audiovisual (págs. 43-49). Manizales: Editorial Universidad de Caldas.

Lyotard, J.-F. 1991. La condición postmoderna Informe sobre el saber. Buenos Aires: R.E.I Argentina S.A.

Proyecto Académico Pedagógico Solidario (PAPS) 2011. Capitulo 2. Material Didáctico. Pg. 112: Universidad Nacional Abierta y a Distancia, UNAD.

Santaella, L. 2007. El arte del silicio. En J. La Ferla, El medio es el diseño audiovisual (págs. 571-573). Manizales: Editorial Universidad de Caldas.

Toledo Castellanos, R. 2012. Tulato, El sentido y el Arte en Colombia. Cuadernos de Música, Artes Visuales y Artes Escénicas, 103-131.

Toledo Castellanos, R. 2011. ¿Es posible un programa de artes a distancia? (R. A. Martínez, Entrevistador)

Toledo Castellanos, R. 2012. Territorios y cuerpos. Codificar/Decodificar. Prácticas, Espacios y Temporalidades del Audiovisual en Internet, 17-35.

Virilio, P. 1995. Ctheory. Recuperado el 05 de 08 de 2014, de Ctheory: www.infoamerica. org/teoria_textos_viriliog5.pdf

Zuleta, E. 2004. Arte y Filosofía. Medellín: Hombre Nuevo Editores. 